\title{
Relationality and rationality in Confucian and Western traditions of thought ${ }^{1}$
}

\section{Professor Yaqing Qin}

China Foreign Affairs University

\section{Dr Astrid H. M. Nordin}

Lancaster University

\begin{abstract}
This paper provides a theoretical sketch of relationality within the field of international relations (IR). It argues, contrary to what many international relations scholars hold, that representation is practice: academic representation reflects the background of a community of practice and highlights what is embodied therein. Therefore, different cultural communities have different practices and draw from different background knowledge. Rationality, which serves as the dominant foundation for background knowledge within many Western communities of practice, permeates through mainstream IR theory. Relationality performs a similar role in many traditionally Confucian communities of practice, where relations enjoy a distinct ontological status over individual rationality. A relational theory assumes (1) that self-existence coincides with other-existence and coexistence, and (2) that self-interest coincides with otherinterest. Based on these assumptions it argues that relations select, meaning that in a social situation actors base their action on relations in the first place and that rationality is and can only be defined and judged in terms of relations. In such a theory, rationality is and can only be defined and judged in terms of relations. The article uses the Association of Southeast Asian Nations (ASEAN) as an example to elaborate its theoretical point.
\end{abstract}

\section{Introduction}

A key source of Anglophone thinking about International Relations (IR) in relational terms has been the broader 'practice turn' in social theory (see Adler and Pouliot 2011a, 2011b; Bueger and Gadinger 2015; see also Nexon and Jackson in this issue). The 'practice turn' established practices as ontological priorities; it emphasized the importance of what a community of practice does in social life (Schatzki 2001). This approach-the International Practice Approach (IPA hereafter)-has sought to focus not on units or subjects but on the practices that shape or produce them. In this article, we suggest that IPA's dualistic structuring of 'background knowledge' and 'representational knowledge' limits its potential as a resource for relational theorising despite the claim that IPA bridges the background and the representational (Adler and Pouliot 2011, 13-14).

Against this backdrop, we propose a theoretical sketch of representation as a relational practice. Our argument progresses in four sections. The first section outlines IPA's dichotomisation of background and representational knowledge and argues, in contrast, that the two cannot be meaningfully separated. To illustrate this point, we use academic communities as an example, suggesting that even academic knowledge relies on

\footnotetext{
1 For helpful comments on earlier drafts of this paper, we thank participants of the workshop Futures of global relations, as well as CRIA's anonymous reviewers.
} 
(geo)cultural communities of practice and the background knowledge that both shapes them and is shaped by them in turn. The second section outlines how many scholars within the Anglophone academic or epistemic community have used rationality to organise their ideas. We use what are often called 'mainstream' IR theories—neorealism, neoliberalism, and constructivism - to illustrate this argument. In contrast, the third section examines how the Sinophone academic or epistemic community have used relationality to organise their ideas. We use Chinese approaches to IR theorising-specifically, the zhongyong dialectic - to illustrate this point. The fourth section further illustrates the prevalence of relational thinking within the Sinophone community through the example of ASEAN as a governing body that reflects a regional community of practice.

To be clear from the outset, we are not advocating a form of cultural essentialism, strategic or otherwise. We do not suggest that rationality is unique to some imagined Western community of practice, nor do we suggest that rationality fully encompasses such an imagined community. One may even argue that the background knowledge we ascribe to 'mainstream' IR theories-neorealism, neoliberalism, and constructivism-only represents a small community of predominantly white, male intellectuals. Many postcolonial and feminist theories, and indeed IPA itself, draw on the same intellectual tradition of this imagined Western community to instead emphasise relationality. Relational thinking, based on an equally imagined 'Confucian' or 'Chinese' tradition, does not fully encompass the intellectual tradition of the 'Sinophone' (geo)cultural community either. In fact, many Sinophone scholars draw on neorealism, neoliberalism, and constructivism-the same theories that foreground rationality. Still, certain terms continue to be dominant or hegemonic in a given (geo)cultural tradition without characterizing 'Western' and 'Chinese' thought as monolithic or opposed to one another (cf. Hall and Ames, 1995). The dominant narrative of modernity in the West is represented mainly as individualistic rationality (advanced, perhaps, by those same white, male intellectuals who claim to represent the Western community). To a large extent, these 'Western' academic practitioners have based their representations predominantly on modern Western thought. With its embedded violence-and despite protests by post-colonial and feminist scholars-modern Western thought has dominated much academic discourse both within China and abroad. A survey by the Project on Teaching, Research, and International Practice (TRIP), for example, has repeatedly shown that IR scholars within the United States have largely continued to view IR through the lenses of realism, liberalism, and constructivism (Sil and Katzenstein 2010, 24-25; Maliniak et al. 2014). Only a genuinely globalist approach with multiculturalism at its core can effectively overcome the dominance of modern Western thought in academic discourse and practice.

Because this article is written as part of a special issue on relational theorising in Anglophone and Sinophone IR, we use a theoretical approach and apply our theory only through limited empirical examples. Readers who want to pursue further and applied reading on this topic may consult, e.g., Qin, 2018, or Nordin and Smith, 2018.

\section{Practicality}


IPA, which has grown in popularity in the last decade, includes several interrelated arguments. First, it gives ontological priority to practice. Second, it argues that practice rests on 'background knowledge', which forms the foundation upon which humans act (Searle 1995). In other words, most of what people do does not derive from conscious deliberation or thoughtful reflection, but from background or tacit knowledge (Pouliot 2008, 258). Many IPA scholars argue that mainstream IR theories of human action 'suffer from a representational bias in that they focus on what agents think about instead of what they think from' (Pouliot 2008, 257). Third, IPA demonstrates that background knowledge is embodied in a 'community of practice', which is 'a configuration of a domain of knowledge that constitutes like mindedness, a community of people that "creates the social fabric of learning," and a shared practice that embodies "the knowledge the community develops, shares, and maintains" (Adler and Pouliot 2011, 17). These communities of practice are social collectives that both develop and share background knowledge and are, in turn, constituted and shaped by such knowledge.

In viewing communities of practice this way, IPA prioritises the role of practice in IR theorising by shifting background knowledge to the foreground. However, the relational thinking that stems from IPA's dichotomisation of 'background knowledge' and 'representational knowledge' - the former referring to the inarticulate and unreflective and the latter to the articulate and deliberate-is flawed. While background knowledge does play a key role in orienting human activity, it is not an independent alternative to representational knowledge. By construing it thus, IPA scholars do not merely present background knowledge as the primary base for human action; they reinforce the view that there are two types of knowledge-background and representational- that exist in parallel or even in binary opposition. By splitting representation from practice, they, like Descartes, also implicitly separate the thinking mind from the doing body.

In contrast, we suggest that background and representational knowledge are not alternatives to one another, but rather are inseparable from one another. Knowledge production, itself, is a practice that relies on the background knowledge of a relational community of practice. Consider an academic community: its members come together in relationships; deliberate and debate; form rules and norms; and act as practitioners in knowledge production and representation. In so doing, they rely on tacit background knowledge-assumptions and understandings that are not explicit in representation and deliberation, but that are inherent to it. In other words, they are shaped by their deliberative and representational practice, whether conscious or unconscious.

At their core, representation and background knowledge are intertwined; they are inseparable. The producer of knowledge is not in isolation but is rather a sociallyconstituted person who builds relationships with others and lives intertwined with the background knowledge of a community of practice. Indeed, a social scholar immersed in a certain community of practice and shaped by the background knowledge thereof would find it near impossible to produce representational knowledge that was absolutely alien to 
such background knowledge.

These relational communities of practice are where background knowledge is embodied, but IPA defines them in quite a narrow sense. Since practice is defined as 'competent performances' (Adler and Pouliot 2011, 6), a community of practice is necessarily more functional than fundamental: it is a grouping that works in a specific issue area (e.g. the diplomatic community). Such a professional community, including the academic community, may indeed share a set of practices and norms, though these practices and norms may be negotiated, evolve, and remain incomplete. We want to suggest, however, that scholars cannot ignore the background knowledge associated with a (geo)cultural community of practice (cf. Bourdieu 2012). (Geo)culturally nurtured background knowledge is typically — though not necessarily — thicker, steadier, and more spontaneous than any professionally and technically formed background knowledge in a certain issue area.

Inspired by both the contributions and limitations of IPA, we propose a (geo)culturally grounded view of relational practice. First, we suggest that relational practice is inseparable from background knowledge. Put differently, much of human activity is oriented 'immediately and effortlessly' by 'nonintentional or preintentional capacities' (Searle 1995, 129 , 132). Second, we suggest that representation is practice, so representational knowledge must therefore be inseparable from background knowledge. Even though background knowledge can never be fully represented by representational knowledge (Schatzki 2001, 8-9), the latter does still represent the former, albeit only partially. Third, we suggest that background knowledge is embodied in a community of relational practice, where (geo)cultural communities are key. In other words, relational community of practice should not be limited to technically defined communities. Fourth, we suggest that any social theory, viewed as a form of representational knowledge, is necessarily entwined with the background knowledge of the (geo)cultural community or communities of practice through which it emerged. In what follows, we use debates around 'rationality' and 'relationality', in turn, to illustrate our view.

\section{Rationality}

If representation is practice and scholars are practitioners, representational knowledge produced by scholars reflects the background knowledge of the (geo)cultural community in which it is produced. Under this view, IR theory-a form of representational knowledge-is also a practice. Balance-of-power theory, for example, relies on the practice of European international relations; no such theory could have grown out of the East Asian tribute system or the Tokugawa international system (Kang 2007; Ringmar 2012). Further, the logics of action represented by mainstream IR theories like neorealism, neoliberal institutionalism, and constructivism (Waltz 1979; Keohane 1984; Wendt 1999) all contain and represent a core concept—individualistic rationality — which rests solidly on the background knowledge of the so-called Western cultural communities these theories have been taken to represent. 
The logics of consequences and appropriateness that form the core of rationalistic and reflective IR theories are based on rationality. The former reflects the rational choice proposition, arguing that human actors 'choose among alternatives by evaluating their likely consequences for personal and collective objectives’ (March and Olsen 1998, 949). It assumes that actors are instrumentally rational with prior preferences and well-defined self-interests. These actors are capable of comparing and calculating policy alternatives and choose the one that maximizes their interests. Olsen (1995) suggests a logic of collective action that falls within the logic of consequences: every actor in a collective-action situation is instrumentally rational, self-interested, and ready to free ride whenever possible. In IR, structural realism and neo-liberal institutionalism are typical examples of this logic as well: the crucial mechanism by which international structures and international institutions influence an actor's behaviour is the actor's instrumental rationality. Only through rationality do the structure of power distribution and international institutions impact actor behaviour. In other words, instrumental rationality is the key for what Keohane (1989) terms the 'rationalistic approach'.

Constructivism offers an alternative argument: the logic of appropriateness drives action. Appropriateness is the sense of doing the right thing or following the right social norms in a particular situation. Rules and norms, which can both constitute an actor's identity and regulate an actor's behaviour, are crucial to this logic (Ruggie 1999). They support both the rationalistic emphasis on behaviour and the constructivist exploration of identity. To date, the logic of appropriateness has mainly focused on norm-guided behaviours-from norm acceptance to norm internalization and then to norm following-using what Hopf terms 'value rationality', which 'implies reference to some norms when making a choice' (2010, 540). Similarly, Finnemore (1996) emphasises how international organisations teach actors good norms: the mechanism of teaching enables alleged newcomers in international society to understand what their interests should be and what behaviour is appropriate. In fact, individualistic rationality applies throughout the process of both norm learning and following: following the norms taught by international organisations is beneficial to actors and subsequently leads them to accept the norms. Risse $(2000,4)$ describes this logic of appropriateness as 'normative rationality'. While instrumental rationality suggests that actors act according to their calculation of gains measured against their fixed interests, normative rationality suggests that human action is rational if and only if it follows the right norms.

The logic of arguing, to a large extent, mirrors the logic of appropriateness; it also emphasises 'better' rules and norms. Drawing on Habermas' communicative action theory, which stresses the importance of argumentative rationality, it holds that 'human actors engage in truth seeking with the aim of reaching a mutual understanding based on a reasoned consensus ... challenging the validity claims involved in any communication' (Risse 2000, 1-2). In other words, actors know there are norms and wish to follow good norms, but must argue in order to know which norms are good and reasonable. Thus, one might say, 'let's argue', find nice norms through arguing, and then follow them. 
Fundamentally, the logic of arguing is a form of normative rationality that emphasises argumentation as an effective way to choose good norms (Kornprobst 2007). This logic is particularly significant in the normative suasion stage of norm socialisation proposed by Checkel (2005), during which social actors follow rules and norms, but do not follow them blindly. The logic involves 'a reflexive process whereby agents need to figure out what behaviour is appropriate to a situation' (Pouliot 2008, 262). Argumentative rationality seeks to guide individual behaviour via good norms, thus making normative rationality even more rational.

Rationality constitutes the basis for all three of these theories, and their associated logics, which differ only in what kind of rationality they use. Neorealism and neoliberal institutionalism use instrumental rationality. Mainstream constructivism uses normative rationality. And no matter if the international structure is material or ideational, it influences actors' behaviour through individualistic rationality. The logic of arguing, too, reinforces normative rationality. Thus, these mainstream IR theories are based on the rationality of individual actors in the international system. In fact, these theories have typically emphasised 'rationality' to such a degree that it has become essential in the representational knowledge of 'mainstream' IR theories, with roots in the imagined 'West'. In Western communities of practice, for example, the individual has always been the pivot in practice. Individual, 'rational' action is central to the background knowledge of such communities of practice; it is embodied in practice and represented in theory. It is therefore no accident that mainstream Anglophone IR theories share this common denominator.

\section{Relationality}

Confucian communities of practice have tended to view the world as one of relations rather than atomistic entities, and the social world as one of human relations rather than discrete individuals (Liang 1949/2011; Hall and Ames 1987). As a result, relationality is a most significant concept abstracted from the cultural and social practices centred around relations and becomes to a large extent a most important element of the background knowledge of Confucian cultural communities of practice. The relational theory that we have proposed herein and elsewhere holds that, to understand social phenomena and meaningful human actions, one must understand relationality (redacted for anonymisation). Relationality is to 'Confucian' communities of practice as rationality is to the imagined 'Western' communities of practice discussed above; for both have been abstracted and represented from and through practice in their respective cultural communities.

Relationality is informed by elements embodied in the practical knowledge of Confucian communities. The first of these elements is co-existence, which states that self-existence is simultaneously co-existence with others. In other words, any individual self is a continuous process between the self and others to whom the self is related. Co-existence contrasts with two ontological positions: one stresses the priority of self-existence over co-existence, which provides the ontological foundation for individualistic rationality (and 
thus for much of the mainstream IR literature), and the other posits that co-existence comes before self-existence (explicitly in Zhao, 2009; implicitly in Jackson \& Nexon, 1999). In the Chinese zhongyong dialectics, 'self' and 'other' are dependent on each other for their existence_or, perhaps better, their becoming (Ling 2013, 2014; Qin, 2016, 2018; Nordin and Smith, 2018). Under this view, humans are more relational 'becomings' than selforganizing beings in a social setting. It can be argued that this implies that the well-related are fitter to survive and the 'harmoniously'-related more likely to prosper-even to the detriment of others (Nordin, 2016).

For co-existence to be the normal state of society, actors must have 'relational identities'. Identities of social actors are shaped by social relations and formed in the process of relating and being related. No absolute and independent identity of the self exists ( $\mathrm{Tu}$ 1985, 114). Rather, it is constructed and reconstructed in relations with others. In this line of thinking, " $[\mathrm{t}]$ here is no me in isolation, to be considered abstractly: I am the totality of roles I live in relation to specific other' (Nisbett 2003, 5). In other words, the self is a 'relational self or a 'self-in-relation-with others' (Ho 1995, 117, emphasis in original). As the Chinese game weiqi or go shows, a piece has no role or identity until it is placed on the chessboard and becomes related to other pieces already there. The Chinese language tells a similar story: there are no nominative and objective cases for a pronoun. The same Chinese character is used for both 'I' and 'me', or for 'he' and 'him'. Whether it is the nominative or the objective depends on its relations to other characters in a sentence. In this way, 'China' or a 'Confucian community of practice' only gains significance through its relation to other communities of practice, such as 'the West' or a 'Western community of practice' (and vice versa). Both communities of practice are products or effects of the international relations between them and with others, as is the very 'international' through which they relate.

In such a situation of relational identities, shared interest arguably becomes a habitual way of thinking. If self-existence is simultaneously co-existence and the identity of the self is formed in relation to others, self-interest is simply impossible to independently define in a social context. It is therefore necessary to challenge the primacy of an independent selfinterest within mainstream IR theories. In a relational community of practice, interest is always shared and realized through reciprocity. Relationality recognizes the legitimacy of self-interest, but argues that self-interest and other-interest are shared in social life and can be defined only in relational terms. Even interest between deadly enemies is shared. For example, the U.S. and U.S.S.R. continued strategic arms negotiations during the Cold War, and, during the First World War soldiers of enemy states deliberately withheld fire during trench warfare (Axelrod 1984, 73-87).

The above are conspicuous elements in an arguably Confucian community of practice and indicate that relations are a pivotal factor in social space. This community of practice relies on the logic of relationality, in which social actors base their actions on relations. In other words, an actor makes judgments and decisions according to his or her relationships to specific - and often significant-others and the relational context in which these 
relationships are embedded. In any social setting, what action an actor is to take depends very much on their relationships with significant others and their relations with the relational context in which they are embedded. In short, relations select.

To apply relationality to real-world examples, we must first clarify a key concept within the logic of Confucian relationality: the relational circle. The self's relational circles are its relationships, starting from the self, who perceives itself at the centre of numerous, concentric, relational circles that indicate the self's relationships with others. With the self as the origin, these relational circles extend outward and throughout the self's social world (Fei 2012). Through its relational circles, the self connects itself to others. The circles constitute the social fabrics where the self is entangled; their social activities occur in, with and through these relational circles.

With this concept in mind, relations select through certain crucial mechanisms, most importantly what may be called the 'intimacy rule', but also mechanisms relating to importance and instrumentality. The intimacy rule hypothesises that the more intimate the relational circle is, the more it influences your decision (Hwang 1987, 2000). The self's relational circles indicate the degree of intimacy of its relationships with others and constitute its sphere of activity. Those within the innermost ring are the self's most intimate others, and the degree of intimacy decreases as the circles move farther away from the centre. Under this view, the most intimate circle of a person is their family (for a discussion of such relationality in the IR context, see Zhang Feng, 2015).

In what follows, we elaborate on this notion of relationality through the example of the Association of Southeast Asian Nations (ASEAN).

\section{ASEAN as an empirical example of relationality}

ASEAN is a good example of how this relational theory, drawing inspiration from what has been called a Confucian cultural community, can help us see the logic of relationality in empirical practice. In contrast to theorists like Samuel Huntington, who (in)famously portrayed civilizational others as diametrically opposed and 'unassimilatable' (Huntington 1996), the relational zhongyong approach from the Confucian community of practice views any two interacting cultures and civilizations as mutually inclusive, each containing elements of the other even though they differ and may seem to be opposite to one another. The inclusive regionalism proposed by ASEAN is an empirical example of this zhongyong approach whereby the self and others are complementary in diversity and coconstitutive (Qin 2016, 40).

We may also use the lens of relational circles to view ASEAN as an example in IR. Its relations include at least three interrelated concentric circles. The first and core circle is ASEAN, which consists of ten member states; the second circle includes neighbouring countries or ASEAN's dialogue partners-initially countries like China, Japan, and South Korea, but gradually extending to include more actors like India, Australia, New Zealand, 
Russia, and the United States; and the third circle may involve any other actors in the world. ASEAN tends to consider its relationships with actors in all of its relational circles before it makes a decision, but the priority is always given to maintaining a cohesive and strong relationship among the members of the core circle. In other words, ASEAN's choice of action is first of all influenced by its most intimate relational circle.

Although intimacy is a key indicator of relational importance, intimacy does not automatically mean that a relationship is important. Another dimension is needed'importance'-which can interfere with intimacy when an actor considers relationships before acting. Typically, the more important your relational partner is, the more your relationship with them influences your decision. While ASEAN usually prioritises relationships with its most intimate core circle when making decisions, its relationships to actors outside of its core circle also vary in importance. For example, the powerful role that the U.S. holds in the region and its significance to ASEAN's security relations with non-ASEAN neighbours like China does not necessarily indicate intimacy with ASEAN countries. Nonetheless, ASEAN may prioritise U.S. needs and demands when making decisions simply because of the importance of the U.S.'s role in the region. Through the lens of zhongyong, cooperation within and across relational circles is a process of cochanging and co-evolution that is often achieved by maintaining, managing, and harmonising relations among actors. Further, zhongyong justifies prioritising the maintenance of the cooperation process as an end in itself-one that is more important than achieving immediate and tangible results. The 'comfort-level' norm among ASEAN member exemplifies this prioritisation of cooperation: any action should proceed at a level that all members are comfortable with. The norm keeps negotiations from breaking down even when serious differences occur (Qin 2016, 37). ASEAN has also developed several practices for creating a sense of shared background knowledge and comfort that enables the cooperation process to continue. In the traditional language of Confucian ethics, these practices are called $l i$, typically translated as 'protocols' or 'rites'. Confucian ethics advocate these protocols as a way to educate actors and instil shared and appropriate 'background knowledge' within officials and scholars that are members of a given community of practice. More broadly, instilling actors with $l i$ is said to be the civilization-wide process behind the formation of complex and ordered societies, which according to many Confucians helps produce good, appropriate, stable, and harmonious relations throughout the social body. ${ }^{2}$

Another mechanism through which relations select is 'relational rationality': whether an actor's action is rational depends on how he or she is related to the specific other toward whom the action is taken. The logic of relationality does not negate the proposition that a social actor can be rational, but argues that an actor's individualistic rationality is necessarily mediated by his or her relationships with others. Before the self understands the nature of an evolving relationship between itself and a specific other, its sense of what actions are

\footnotetext{
2 We thank an anonymous reviewer for the suggestion to highlight this broader civilizational significance. We also point out that this societal harmonisation has been critiqued by students of this Confucian tradition (e.g. Nordin, 2016).
} 
rational or irrational is particularly limited. Rational actions are typically viewed as those serving one's self-interest, but self-interest is shared, defined, and gained through social relations. Thus, rationality is meaningful only when it is defined in terms of relationality. Compared with rationality, therefore, relationality enjoys ontological priority.

The proposition that rationality is relational applies to instrumental rationality as well. The idea that people seek to maximise their self-interest has become a widely accepted principle of instrumental rationality. Under a theory of relationality, however, the self-interest assumed by the rational choice model may not be rationally constructed because it doesn't consider what kind of relationship the self has with the specific other. Consider the classical Prisoner's Dilemma (PD) game in which each prisoner has his or her own interest and thinks about how most rationally he or she can realize his or her interest in a strategic interaction with the other prisoner. Paraphrasing Schelling (1980, 84), we should not expect the rational strategies pursued by two individual players in a situation of pure conflict to reveal what kind of behaviour they might pursue in a relational world (i.e. one where relations matter). From the very beginning of the PD interaction, relational rationality differs in that the players know their interest-and thus 'rationality' more broadly-is defined and achieved in terms of relations. Defection is rational in a single-move PD game but irrational when the players have known each other and expect to play the game repeatedly in the future. Because they are no longer strangers and have begun to build relations, their rational choices change. Thus, Pouliot argues, 'while it makes sense for a Westerner to be instrumentally rational when planning investment in the economic field, it is quite nonsensical (and socially reprehensible) to constantly calculate means and ends with family and friends' (Pouliot 2008, 276). In this sense, the nature of relationships informs what is instrumentally rational and what is not. Further, we can extend this logic to some of our examples of relational circles above. For example, ASEAN will behave differently in relation to other members of the ASEAN 'family' compared to, say, Australia or Iceland.

Normative rationality is also relational. Without clearly perceiving the nature of a relationship, the actor does not know what and whose norms he or she should follow when making decisions. The nature of the relationship defines the appropriateness of an action. In Confucianism, ren is the most important moral and social norm-something that recent IR theorising has recognized as well (Qin, 2018, Song, 2001). While ren is often translated as 'humaneness', 'benevolence', or 'virtue', no single English translation encapsulates its real meaning. Instead, ren is expressed in different forms for different relationships. For instance, the parent-child relationship dictates that the son should follow the norm of family reverence. The friend-friend relationship stipulates that friends should follow the norm of sincerity (for further elaboration on friendship as a relational ontology, see Nordin and Smith, 2018). Filial piety in the former and sincerity in the latter are both expressions of the moral norm of ' $r e n$ '. As Hwang argues, 'an individual will employ different rules of social exchange to interact with people of different types of relationships or different degrees of intimacy' (Hwang 1987, 949). Fei also holds that, in a Confucian society, 'general standards have no utility. The first thing to do is to understand the specific 
context: Who is the important figure, and what kind of relationship is appropriate with that figure? Only then can one decide the ethical standards to be applied in that context' (Fei 2012, 68). At a normative level, we can also view ren through ASEAN's relational circles. Not only is it rational for ASEAN countries to behave differently in relation to other members of the ASEAN 'family' than they do towards Australia or Iceland, but it's also ethically appropriate within the bounds of ren for ASEAN member-states to treat other member differently than non-members due to their different types of relations, levels of intimacy, and degrees of importance.

Even though the logic of relationality is representational knowledge, it has both grown out of and represents the background knowledge of Confucian communities of practice. In these communities of thought, people think primarily about, from, and in terms of relations. Not all decisions that ASEAN member-states make are determined by relationality, but relationality does influence decision-making in many Confucian communities of practice. Many scholars who are connected to Confucian communities of practice are also more attuned to recognise these tendencies - even if they do not originate from or practice within these communities.

Of course, ASEAN is only one empirical example of relational circles. China's partnership diplomacy, with more than 80 countries and regional organisations in the world that form 'circles of partners', is another. These partnership relations break down into four circles ranked from most to least intimate: comprehensive strategic partners, strategic partners, comprehensive cooperative partners, and partners. China may adopt certain behaviours in relation to its 'comprehensive strategic partners' (such as the E.U., for example) that it would not adopt in relation to less intimate relations like simple 'partners'. However, it is not always clear what these relationships actually signify or what their effect might be in any given interaction. The prioritising role of 'importance' could likewise be illustrated by the Cold War years, when the U.S. viewed the Soviet Union as its most important bilateral relationship, even though the actors' degree of intimacy was negative. Further, the U.S. decision to establish diplomatic relations with mainland China and sever its official relations with Taiwan in the 1970s indicates that it considered its relationship with the mainland as more important than its relationship with Taiwan (although the time delay and heated debate before the U.S. made its decision suggests that actors may feel conflicted when weighing their relationships with specific others when intimacy conflicts with importance).

\section{Conclusion}

Representational and background knowledge are intertwined in communities of practice. They shape and adapt the theories developed within their communities. It is no accident that individualistic rationality constitutes a theoretical hard core for mainstream Western IR theories as well as for social theories in other disciplines, for the logic of rationality has been deeply embodied in the practice of Western communities and recurrently refined and represented by mainstream knowledge producers into an intellectual core that sustains and 
dominates much of the discourse of the social sciences from economics to political science. Throughout this process, representational and background knowledge complement and reinforce each other through knowledge practice and production.

Scholars of Confucian cultural communities of practice have rarely represented individualistic rationality as core in their academic pursuit. For millennia, scholars in Confucian communities preferred to focus instead on relations among all under heaven, but especially human relations in the social world. It is relationality that has been the topic for extensive discussion and sophisticated analysis in classical works of intellectual significance. It is no accident either, for a Confucian society is often said to be a 'relational society' where 'human relations' characterize practice.

It is important to note that the emphasis on relations is by no means a negation of rationality. The logic of relationality recognizes the important role played by rationality, but accentuates that rationality is significant only when defined in terms of relationality, or 'relational rationality'. It means that whether an actor's action is rational depends on how she is related to the specific other toward whom the action is taken. The logic of relationality does not negate the proposition that a becoming social actor can be rational, instrumentally or normatively, but argues that her individualistic rationality is necessarily mediated by her relationships with others in the first place. Rationality is thus defined in terms of relationality. Before the self is clear about the nature of an evolving relationship between herself and the specific other, her sense of what actions are rational or irrational is particularly limited. It is generally understood that rationality is about serving one's self-interest, but self-interest is shared, defined and gained through social relations. Thus, rationality is meaningful only when it is defined in terms of relationality. Compared with rationality, therefore, relationality arguably enjoys ontological priority.

Background knowledge is intertwined with disparate communities of practice and shapes ways of thinking and doing representational knowledge. The latter in turn represents, reinforces and rationalizes the former as well as the practice in which it is embodied. One possible implication for social theory, therefore, is that a certain level of bounded universality is achievable, while perfect validity across time and space is utopian. It does not mean, however, that a social theory cannot go beyond its native origins. Rationality has been widely accepted as a core concept for social studies far beyond the West, and relationality, though a very much underexplored concept, has great potential. After all, to relate is human. Moreover, rationality and relationality are not dichotomous oppositions; rather they are inclusive of each other. The simultaneity of self-existence and coexistence entails that individualistic rationality is important, but it is not important on its own. Only when defined in terms of relationality does it become socially significant. 


\section{References}

Adler, Emanuel and Vincent Pouliot (eds) (2011a) International practice (Cambridge: Cambridge University Press)

Adler, Emanuel and Vincent Pouliot (2011b) 'International Practices' International Theory 3 (1):1-36

Axelrod, Robert (1984) The evolution of cooperation (New York: Basic Books)

Bourdieu, Pierre (2012) 'Structure, habitus, practices" in Craig Calbourn et al (eds) Contemporary sociology theory (UK: Wiley-Blackwell) 345-58

Bueger, Christian and Frank Gadinger (2015) 'The Play of International Practice' International Studies Quarterly 59 (3):449-60.

Checkel, Jeffrey (2005) 'International institutions and socialization in Europe: introduction and framework", International Organization, 59 (Fall), 801-826

Fei, Xiaotong (2012) From the soil: the foundation of Chinese society (Beijing: Foreign Language Teaching and Research Press)

Finnemore, Martha (1996) National interests in international society (Ithaca: Cornell University Press)

Hall, David and Roger Ames (1987) Thinking through Confucius (New York: State University of New York Press)

Hall, David and Roger Ames (1995). Anticipating China : thinking through the narratives of Chinese and Western culture. Albany, State University of New York Press.

Ho, David Y. F. (1995) 'Selfhood and identity in Confucianism, Buddhism, and Hinduism: contrasts with the West', Journal for the Theory of Social Behaviour 25 (2), 115-139

Hopf, Ted (2010) 'The logic of habit in international relations', European Journal of International Relations, 16 (4), 539-561

Huntington, Samuel (1993) 'The clash of civilizations?’ Foreign Affairs (Summer 1993), 22-49

Hwang, Kwang-kuo (1987) 'Face and favour: the Chinese power game' American Journal of Sociology 92 (4), 944-974

Hwang, Kwang-kuo (2000) 'Chinese relationalism: Theoretical construction and methodological considerations', Journal for the Theory of Social Behaviour, 30(2), 155-178

Jackson, Patrick T. and Daniel H. Nexon (1999) 'Relations before states: substance, process, and the study of world politics', European Journal of International Relations 5 (3), 291-332

Kang, David (2007) China rising: peace, power, and order in East Asia (New York: Columbia University Press)

Keohane, Robert (1984) After hegemony (Princeton: Princeton University Press)

Keohane, Robert (1989) 'International institutions: two approaches' in Robert Keohane (eds) International institutions and state power (Boulder, Westview), 158-179

Kornprobst, Markus (2007) 'Argumentation and compromise: Ireland's selection of the territorial status quo norm', International Organization, 61 (Winter), 69-98

Liang, Shuming (1949/2011) Zhongguo wenhua yaoyi (Essence of Chinese culture) (Shanghai: Shanghai Publishing House)

Ling, L. H. M. (2013). "Worlds beyond Westphalia: Daoist dialectics and the 'China threat'." Review of International Studies 39(3): 549-568.

Ling, L. H. M. (2014). The Dao of world politics: towards a post-Westphalian, worldist international relations. Abingdon, Routledge.

Maliniak, Daniel, Susan Peterson, Ryan Powers and Michael J. Tierney (2014) TRIP 2014 faculty survey (Williamsburg, VA: Institute for the Theory and Practice of International Relations), < https://trip.wm.edu/reports/2014/rp 2014/>, accessed 
24 June 2016

March, James and Johann Olsen (1998) 'The institutional dynamics of international politics orders', International Organization, 52 (4), 943-969

Nisbett, Richard (2003) The geography of thought: how Asians and Westerners think differently ... and why (New York: Free Press)

Nordin, Astrid H. M. (2016). China's International Relations and Harmonious World: Time, space and multiplicity in World Politics. Abingdon and New York, Routledge.

Nordin, Astrid H. M. and Graham M. Smith (2018). "Reintroducing friendship to international relations: relational ontologies from China to the West." International Relations of the Asia Pacific 18(3): 369-396.

Olson, Mancur (1995) The logic of collective action (Cambridge, MA.: Harvard University Press)

Pouliot, Vincent (2008) 'The logic of pacticality: a theory of practice of security communities', International Organization, 62 (2), 257-288

Qin, Yaqing (2016) 'A relational theory of world politics', International Studies Review, 18, 33-47

Qin Yaqing (2018) A Relational Theory of World Politics. Cambridge, Cambridge University Press

Ringmar, Erik (2012) 'Performing international systems: two East-Asian alternatives to the Westphalian order', International Organization, 66 (1), 1-25

Risse, Thomas (2000) “'Let's argue!”: communicative action in world politics', International Organization, 54 (Winter), 1-39

Ruggie, John (1999) 'What makes the world hang together? neo-utilitarianism and the social constructive challenge' in Peter Katzenstein, Robert Keohane, and Stephen Krasner (eds) Exploration and contestation in the study of world politics (Cambridge, MA.: The MIT Press), 215-245

Schatzki, Theodore R. (2001) 'Introduction: practice theory' in Theodore R. Schatzki, Karin Knorr Cetina, and Eike Von Savigny (eds) The practice turn in contemporary theory (London and New York: Routledge), 1-14

Schelling, Thomas (1980) The strategy of conflict (Cambridge, MA.: Harvard University

Press)

Searle, John (1995) The construction of social reality (New York: The Free Press)

Sil, Rudra and Peter Katzenstein (2010) Beyond paradigms: analytical eclecticism in the study of world Politics (London and New York: Palgrave Macmillan)

Song Xinning (2001) 'Building international relations theory with Chinese characteristics', Journal of Contemporary China 10(26), 61-74

Swidler, Ann (2001) 'What anchors cultural practices' in Theodore R. Schatzki, Karin Knorr Cetina, and Eike Von Savigny (eds) The practice turn in contemporary theory, 74-92

Tu, Wei-Ming (1985) Confucian thought: selfhood as creative transformation (Albany: State University of New York Press)

Waltz, Kenneth (1979) Theory of international politics (Boston: Addison-Wesley)

Wendt, Alexander (1999) Social theory of international politics (Cambridge: Cambridge University Press)

Zhang Feng (2015). Chinese hegemony: grand strategy and international institutions in East Asian history (Stanford: Stanford University Press)

Zhao, Tingyang (2009) 'Gongzai cunzai lun: renji yu xinji (Ontology of coexistence: contigo and facio)', Zhexue Yanjiu (Philosophical Researches), 8, 22-30 